\title{
Morphologic variations of the second cervical vertebra in Down syndrome compared with age-matched peers
}

\author{
Ryan C. Hofler, MD, MS, ${ }^{1}$ Daniel M. Heiferman, MD, ${ }^{1}$ Ayrin Molefe, PhD, ${ }^{2}$ Ryan LeDuc, BS, ${ }^{3}$ \\ Stephen J. Johans, MD, ${ }^{1}$ Jordan D. Rosenblum, MD, ${ }^{4}$ Russ P. Nockels, MD, ${ }^{1}$ and \\ G. Alexander Jones, MD'
}

Departments of ${ }^{1}$ Neurosurgery and ${ }^{4}$ Neuroradiology, Loyola University Medical Center, Maywood; ${ }^{2}$ Clinical Research Office, Loyola University Chicago Health Sciences Division, Chicago; and ${ }^{3}$ Stritch School of Medicine, Loyola University Chicago, Illinois

OBJECTIVE Atlantoaxial instability is an important cause of pain and neurological dysfunction in patients with Down syndrome (DS), frequently requiring instrumented fusion of the upper cervical spine. This study provides a quantitative analysis of C2 morphology in DS patients compared with their peers without DS to identify differences that must be considered for the safe placement of instrumentation.

METHODS A retrospective chart review identified age-matched patients with and without DS with a CT scan of the cervical spine. Three-dimensional reconstructions of these scans were made with images along the axis of, and perpendicular to, the pars, lamina, facet, and transverse foramen of C2 bilaterally. Two of the authors performed independent measurements of anatomical structures using these images, and the average of the 2 raters' measurements was recorded. Pedicle height and width; pars axis length (the distance from the facet to the anterior vertebral body through the pars); pars rostrocaudal angle (angle of the pars axis length to the endplate of C2); pars axial angle (angle of the pars axis length to the median coronal plane); lamina height, length, and width; lamina angle (angle of the lamina length to the median coronal plane); and transverse foramen posterior distance (the distance from the posterior wall of the transverse foramen to the tangent of the posterior vertebral body) were measured bilaterally. Patients with and without DS were compared using a mixed-effects model accounting for patient height.

RESULTS A total of 18 patients with and 20 patients without DS were included in the analysis. The groups were matched based on age and sex. The median height was $147 \mathrm{~cm}$ (IQR 142-160 cm) in the DS group and $165 \mathrm{~cm}$ (IQR $161-172 \mathrm{~cm})$ in the non-DS group ( $\mathrm{p} 0.001)$. After accounting for variations in height, the mean pars rostrocaudal angle was greater $\left(50.86^{\circ}\right.$ vs $\left.45.54^{\circ}, p=0.004\right)$, the mean transverse foramen posterior distance was less $(-1.5 \mathrm{~mm}$ vs +1.3 $\mathrm{mm}, \mathrm{p}=0.001)$, and the mean lamina width was less $(6.2 \mathrm{~mm}$ vs $7.7 \mathrm{~mm}, \mathrm{p}=0.038)$ in patients with DS.

CONCLUSIONS Patients with DS had a steeper rostrocaudal trajectory of the pars, a more posteriorly positioned transverse foramen posterior wall, and a narrower lamina compared with age- and sex-matched peers. These variations should be considered during surgical planning, as they may have implications to safe placement of instrumentation. https://thejns.org/doi/abs/10.3171/2018.8.SPINE18750

KEYWORDS anatomic variation; axis morphology; Down syndrome; spine; x-ray computed tomography; congenital

$\mathrm{D}$ Own syndrome (DS) is one of the most common genetic disorders in humans, occurring in approximately 1 in every 700 live births. ${ }^{21}$ This syndrome is characterized by numerous abnormalities, including developmental delay, short stature, distinctive facial features, and numerous orthopedic conditions. , $^{3,10,12,18,23,27,28}$ Instability of the upper cervical spine and craniocervical junction, caused by ligamentous laxity, is an important cause of pain, torticollis, and neurological dysfunction in these patients. ${ }^{7,10}$ While surgical intervention with spinal cord decompression, deformity reduction, internal fixation, and fusion is at times warranted to address upper cervical instability in this patient population, it is often fraught with complications, poor outcomes, and need for reoperation. $5,13,20,22,24$

Variations in the anatomy of the second cervical ver- 
tebra present important considerations for safe pedicle, pars, and laminar screw placement. Radiographic studies of the pedicles in healthy patients have been performed and have shown a wide range of variability even within patients unaffected by conditions such as DS.$^{9,25,26}$ In addition, several studies have illustrated anatomical variances within the upper cervical spine in patients with DS..$^{12,27} \mathrm{In}$ spite of this, to date, no formal radiographic or anatomical studies have been performed to identify the variations in the anatomy of the pars, pedicle, and lamina in the DS population. Most of the studies that have been performed to identify bony anomalies in this patient population either occurred in the pre-CT era or primarily utilized plain radiographs. ${ }^{11,12,14,15,17}$ This study presents a morphometric analysis of the pars, pedicle, lamina, and transverse foramen of C2 in patients with DS, with a comparison to their peers without DS, in order to identify differences relevant to surgical decision-making.

\section{Methods \\ Study Design}

A retrospective chart review of patients with DS evaluated at any clinic or hospital setting at our institution between January 2007 and December 2017 was conducted. Patients with CT images including the upper cervical spine were identified. Inclusion criteria were age 16 to 65 years at the time of CT scanning and diagnosis of DS. Exclusion criteria were CT slice thickness greater than $2 \mathrm{~mm}$, poor CT quality, significant degenerative disease, traumatic injury, or postsurgical changes involving the atlas or axis. Patients were excluded for poor CT quality if artifact from motion or foreign body obscured $\mathrm{C} 1$ or $\mathrm{C} 2$. An age- and sex-matched control cohort of patients without DS was identified by review of the first 25 cervical CT scans obtained at our institution in January 2018. The same exclusion criteria were applied to the DS and control groups. The CT scans of the control and DS cohorts were analyzed using InteleViewer 4.12.1 (Intelerad).

Three-dimensional reconstructions were made from each patient's CT scan in InteleViewer in order to obtain reconstructed cuts, in 3 planes, through the body, transverse foramen, pars, pedicle, and lamina of C2. Measurements of these structures were carried out independently by 2 of the authors (R.C.H. and D.M.H.). Each reviewer took a single measurement of the left and right sides of each structure. The measurements from both reviewers were averaged to produce one final right- and left-sided measurement for each dimension analyzed.

The project protocol was reviewed and approved by the Loyola University institutional review board. Given the retrospective nature of the protocol, the requirement for consent was waived.

\section{Measurements}

For each patient, 10 measurements of the right and left pars, lamina, and transverse foramen were made. The pars and pedicle dimensions included the pars rostrocaudal angle, pars axial angle, pars axis length, pedicle width, and pedicle height. These measurements were adapted from the study of cervical pedicles in normal human specimens by
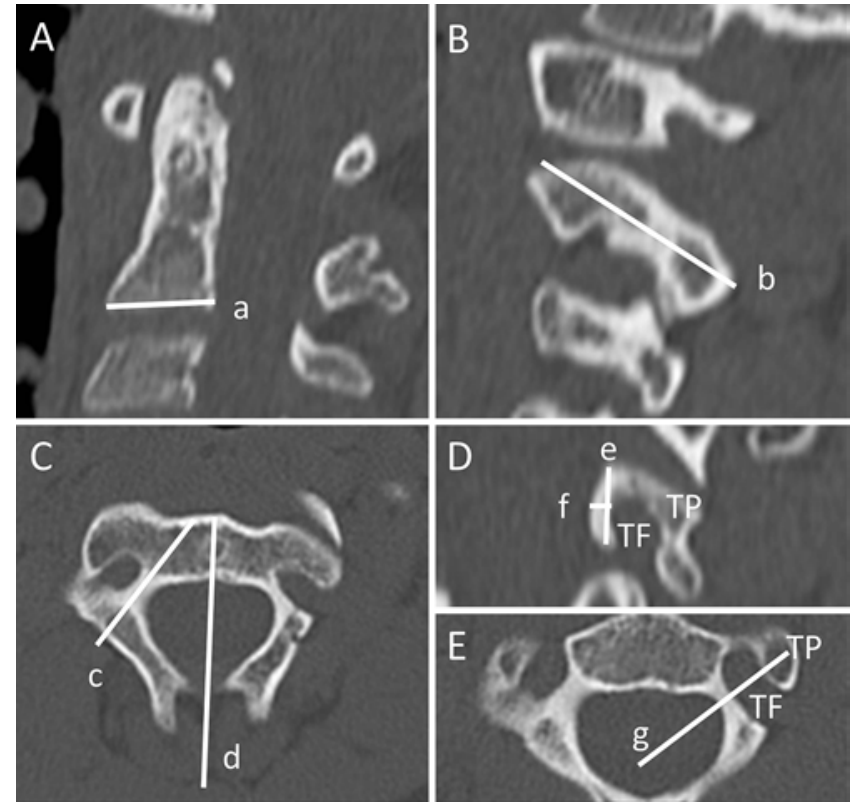

FIG. 1. CT scan of the upper cervical spine demonstrating measurement of the dimensions and angles of the pars and pedicle. A: Midsagittal view through the atlas and axis, with line a representing the plane of the endplate of the axis. B: Sagittal view through the pars and pedicle of the axis, with line $b$ representing the course of the pars and pedicle. The pars rostrocaudal angle is the angle between lines $a$ and $b$. $C$ : Axial view through the axis at the level of the pedicle. Line $c$ represents the pars axis length. Line $d$ represents the midline. The pars axial angle is the angle between lines $c$ and $d$. D: View perpendicular to the pedicle. The pedicle height is line $e$ and the pedicle width is line $f$. The transverse foramen (TF) and transverse process (TP) are also visible. E: Axial view with line $g$ representing the plane of the image seen in panel $D$.

Karaikovic et al. ${ }^{9}$ The pars rostrocaudal angle represents the slope of the pars and was defined as the angle between a line along the plane of the inferior endplate of $\mathrm{C} 2$ and a line parallel to the longitudinal axis of the pars of $\mathrm{C} 2$. This angle was measured on a sagittal view through the pars. The pars axis length was measured as the length of a line along the pars from the outer cortical surface of the lateral mass to the outer cortical surface of the anterior body. This measurement was made on an off-axial reconstructed cut through the plane of the pars. The pars axial angle was defined as the angle of the pars axis length to an anteroposterior line bisecting the $\mathrm{C} 2$ body, as measured on an axial view. The pedicle width and height were measured as the mediolateral and rostrocaudal dimensions, respectively, of the smallest cross-section perpendicular to the pars. Figure 1 illustrates the pars measurements as described.

Measurements of the lamina included the lamina angle, lamina length, lamina width, and lamina height. The lamina angle was defined as the angle of the lamina to an anteroposterior line bisecting the body of $\mathrm{C} 2$, measured on a near-axial cut through the plane of the lamina. The lamina length was measured on the same reconstructed cut as the lamina angle and was defined as the distance along the lamina from the lateral mass to the midline of the spinous process. The lamina width and height were measured as the mediolateral and rostrocaudal dimensions of the smallest cross-section perpendicular to the 

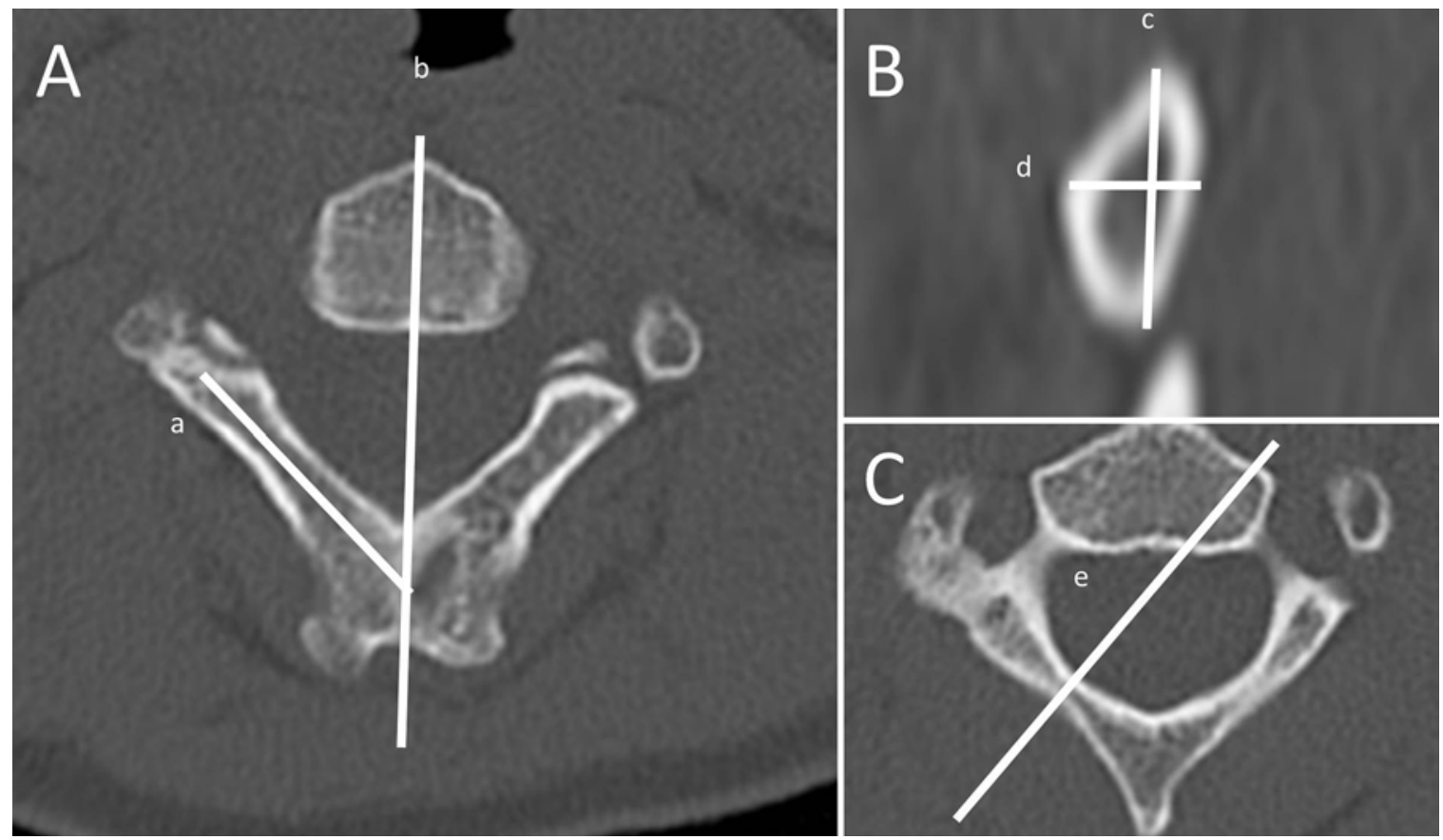

FIG. 2. CT scan of the upper cervical spine demonstrating measurement of dimensions and angle of the lamina. A: Axial view with line $a$ being the lamina length and line $b$ representing the midline. The lamina angle is the angle between lines $a$ and $b$. B: View perpendicular to the lamina. Lamina height is line $c$ and lamina width is line $d$. C: Axial view with line e representing the plane of the image seen in panel B.

lamina, respectively. Figure 2 illustrates these lamina measurements as described.

The transverse foramen posterior distance was measured on a near-axial reconstructed view through the body of $\mathrm{C} 2$ and perpendicular to the axes of the transverse foramina. A line tangent to the outer cortex of the posterior wall of the body was made. The distance from the posterior wall of the transverse foramen to this line was measured. This distance was defined as positive if the posterior wall of the foramen was anterior to the tangent and negative if it was posterior to the tangent. Figure 3 further illustrates how this measurement was performed.

\section{Statistical Analysis}

Characteristics of patients were compared between those with and without DS using Fisher's exact test for equality of proportions for sex and the Wilcoxon ranksum test of equality of medians for age and height. An intraclass correlation coefficient was used to assess interobserver agreement between 2 reviewers' measurements of the $\mathrm{C} 2$ anatomical features on each side (left or right). Interobserver agreement was graded as poor, fair, good, or excellent based on the methodology described by Fleiss. ${ }^{8}$ For each structure, measurements obtained by the 2 raters were averaged to form a composite score for each combination of patient and side. This average score was then used as outcome in all subsequent analyses. Associations between DS and each of the 10 measurements were examined by fitting a mixed-effects regression model separately for each outcome. Associations were estimated first without controlling for patient height and then controlling for height by including height as a fixed effect within the model. To account for correlations between repeated measurements obtained in the same patient, we used mixedeffects models with side as a fixed effect and patient as a

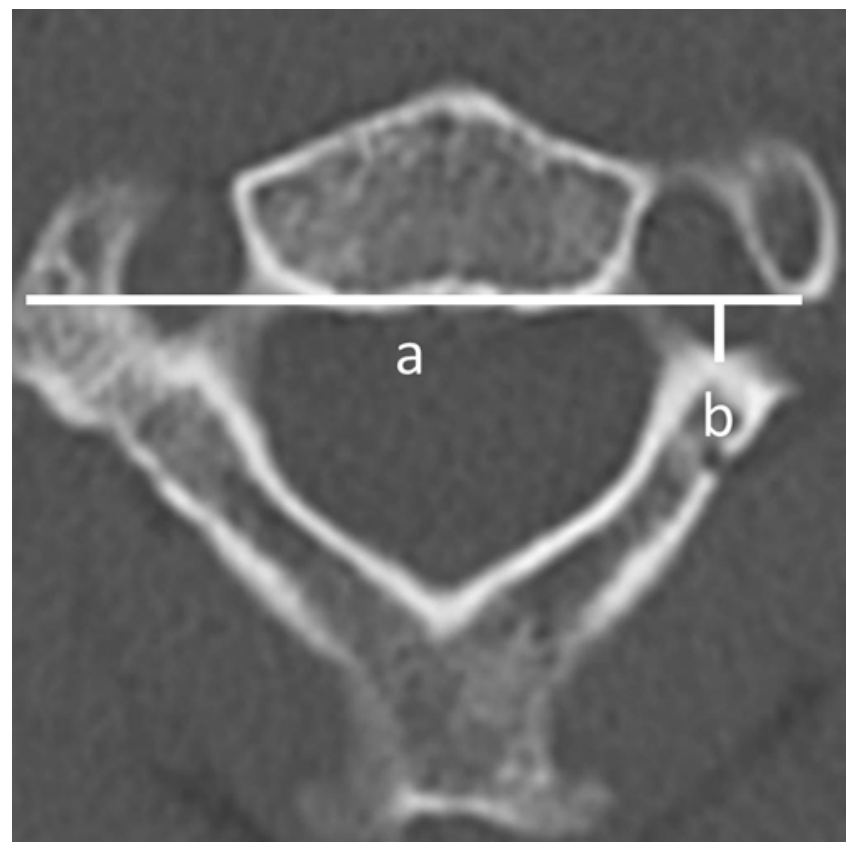

FIG. 3. CT scan of the upper cervical spine demonstrating measurement of the transverse foramen position. Line $a$ is tangent to the posterior wall of the vertebral body. Line $b$ is the transverse foramen posterior distance, measured from the tangent line a to the posterior wall of the transverse foramen. 
TABLE 1. Patient characteristics

\begin{tabular}{|c|c|c|c|c|}
\hline Characteristic & Total & Down Syndrome & Control & $\mathrm{p}$ Value \\
\hline No. of patients & 38 & 18 & 20 & \\
\hline Sex, n (\%) & & & & $>0.99^{*}$ \\
\hline M & $19(50.0)$ & $9(50.0)$ & $10(50.0)$ & \\
\hline $\mathrm{F}$ & $19(50.0)$ & $9(50.0)$ & $10(50.0)$ & \\
\hline Median age (IQR), yrs & $40.5(28-54)$ & $44.5(30-54)$ & $35.5(26-52)$ & $0.693 \dagger$ \\
\hline Median height (IQR), cm & $160(150-165)$ & $147(142-160)$ & $165(161-172)$ & $<0.001 \dagger$ \\
\hline
\end{tabular}

random effect. For each outcome, a model that included a side by DS interaction was first fitted to check if the association between DS and the outcome varied by side. When the interaction term was not statistically significant, it was dropped from the model and a common association was estimated for both sides. When the interaction term was statistically significant, it was retained in the model, and the DS effect was then estimated separately for each side. To protect against spurious findings due to multiple hypothesis tests conducted on the same sample, $p$ values for both the adjusted and unadjusted analyses were corrected using the Sidak method.

Because the 10 outcomes were measured on different scales (e.g., degrees, $\mathrm{mm}$ ) and also have varied ranges and variabilities, differences between DS and non-DS patients are reported in terms of raw scale units as well as in standard deviation units. Effect size (ES) was calculated as the raw difference in means divided the pooled standard deviation of the outcome in DS and non-DS patients (Hedges' $\mathrm{g}$ effect size).

\section{Results}

\section{Patient Characteristics}

A total of 951 patients with DS were identified. Of these, 24 patients met the inclusion criteria. Five patients were excluded due to CT slice thickness greater than $2 \mathrm{~mm}$, and 1 was excluded due to poor CT quality. The final study group included 3 patients with congenital bony anomalies

\section{TABLE 2. Indications for imaging}

\begin{tabular}{lcc}
\hline \multirow{2}{*}{ Indication } & \multicolumn{2}{c}{ No. of Patients } \\
\cline { 2 - 3 } & DS & Non-DS \\
\hline Trauma & 5 & 16 \\
\hline Chronic neck pain & 2 & 2 \\
\hline History of subaxial fusion & 1 & 1 \\
\hline Subaxial stenosis & 1 & \\
\hline Otolaryngological pathology & 4 & \\
\hline Evaluation of neurological dysfunction unrelated & 3 & \\
$\quad$ to cervical spine & & \\
\hline Atlantoaxial rotatory subluxation & 1 & \\
\hline Special Olympics screening & 1 & \\
\hline Syncope & \multicolumn{2}{c}{1} \\
\hline
\end{tabular}

of the craniocervical junction; all 3 of these patients had an incomplete posterior $\mathrm{C} 1$ arch and 1 also had atlantooccipital assimilation. No patients had os odontoideum or significant cranial settling. Only 1 of the DS patients had a diagnosis of atlantoaxial instability, characterized by an atlantoaxial rotatory subluxation. The remaining patients had no symptomatic pathology attributable to the upper cervical spine or craniocervical junction. Of the 25 patients initially identified for the control group, 3 patients were excluded due to degenerative disease involving the atlas and axis, and 2 were excluded due to poor-quality scans. A total of 18 patients with DS and 20 without were included in the analysis. The 2 groups were well matched for age and sex, but there was a statistically significant difference in height. Patients with DS were, on average, shorter than patients in the control group (median $147 \mathrm{~cm}$ vs $165 \mathrm{~cm}, \mathrm{p}<0.001)$. Table 1 summarizes the characteristics of each group, and the indications for imaging are summarized in Table 2. The mean for each measurement is presented by cohort in Table 3 with $\mathrm{p}$ values for heightadjusted and non-height-adjusted comparisons between patients with and without DS.

\section{Unadjusted Analysis}

When height is not accounted for, patients with DS had significantly smaller measurements on 6 of the 10 measured features compared with patients in the control group. Lamina height $(\mathrm{ES}=-1.39, \mathrm{p}=0.001)$ and width $(\mathrm{ES}=-1.27, \mathrm{p}=0.001)$, pedicle height $(\mathrm{ES}=-1.52, \mathrm{p}<$ $0.003)$, pars axial angle $(\mathrm{ES}=-1.15, \mathrm{p}=0.003)$ and axis length $(\mathrm{ES}=-1.08, \mathrm{p}=0.013)$, and the transverse foramen posterior distance $(\mathrm{ES}=-2.17, \mathrm{p}<0.001)$ were significantly smaller in patients with DS. Patients with DS also had a larger pars rostrocaudal angle $(E S=1.07, p=0.012)$ than those without. Table 4 shows the estimated regression coefficients (labeled "difference") of DS as well as the corresponding ESs for each of the 10 measurements, without accounting for patient height. Estimates were derived from a mixed-effects model with DS and side (left vs right) as fixed effects and patient as a random effect.

\section{Height-Adjusted Analysis}

After height was taken into account, only 3 of the 10 measured features remained statistically different for patients with DS compared with control patients (Table 5): lamina width $(\mathrm{ES}=-1.25, \mathrm{p}=0.038)$ and transverse 
TABLE 3. Mean measurements

\begin{tabular}{|c|c|c|c|c|}
\hline \multirow[b]{2}{*}{ Measurement } & \multicolumn{2}{|c|}{ Mean (SD) } & \multicolumn{2}{|c|}{$p$ Value } \\
\hline & DS & Control & Unadjusted & Height Adjusted \\
\hline Lamina angle, $^{\circ}$ & $47.02(3.60)$ & $48.18(3.35)$ & 0.953 & $>0.99$ \\
\hline Lamina height, mm & $10.7(2.0)$ & $13.3(1.7)$ & 0.001 & 0.331 \\
\hline Lamina length, mm & $26.2(2.0)$ & $27.6(1.8)$ & 0.136 & 0.964 \\
\hline Lamina width, mm & $5.0(0.9)$ & $6.5(1.2)$ & 0.001 & 0.038 \\
\hline Pedicle height, mm & $7.9(1.5)$ & $10.0(1.3)$ & $<0.001$ & 0.072 \\
\hline Pedicle width, mm & $6.2(1.3)$ & $7.7(1.9)$ & 0.051 & 0.997 \\
\hline Pars axial angle, ${ }^{\circ}$ & $30.17(5.21)$ & $35.72(4.49)$ & 0.003 & 0.053 \\
\hline Pars axis length, $\mathrm{mm}$ & $27.4(2.4)$ & $30.0(2.3)$ & 0.013 & 0.766 \\
\hline Pars rostrocaudal angle, ${ }^{\circ}$ & $50.86(5.69)$ & $45.54(4.20)$ & 0.012 & 0.004 \\
\hline Transverse foramen posterior distance, $\mathrm{mm}$ & $-1.5(1.3)$ & $1.3(1.2)$ & $<0.001$ & 0.001 \\
\hline
\end{tabular}

Boldface type indicates statistical significance.

foramen posterior distance $(\mathrm{ES}=-1.61, \mathrm{p}=0.001)$ were smaller for DS patients, while the pars rostrocaudal angle was larger $(\mathrm{ES}=1.57, \mathrm{p}=0.004)$.

\section{By Side Analysis}

For each outcome, a model that included a side by DS interaction was first fitted to check if the DS effect varied by side. Prior to adjusting for height, this interaction was only significant for lamina length $(\mathrm{p}=0.047)$. As a result, it was dropped from the models for the other 9 measurements. The interaction for side was retained in the model for lamina length only, and the effect of DS on lamina length was estimated separately for each side, as well as overall. Table 4 summarizes the result of this latter analysis, which showed a significant difference for the left lamina length $(p=0.003)$, but not the right $(p=0.104)$. In the analysis adjusting for height (Table 5), the effect of DS on lamina length was similarly estimated separately for each side; however, after adjusting for height, neither the left ( $\mathrm{p}$ $=0.622)$ nor the right $(p=0.116)$ association between DS and lamina length was statistically significant.

\section{Interobserver Reliability}

Interobserver agreement was found to be excellent for bilateral lamina height and width, pedicle width, transverse foramen posterior distance, and right-sided pedicle height. Agreement was good for bilateral lamina angle and length. Agreement was fair for left-sided pedicle height and poor for pars axial angle, pars axis length, and pars rostrocaudal angle.

\section{Discussion}

The present study was conducted to quantify anatomical variations in C2 of patients with DS. This represents the first study to date to quantitatively evaluate the surgically important structures of the axis in DS.

Karaikovic et al. ${ }^{9}$ performed an evaluation of the anatomical features of the cervical pedicles in normal human cadavers. Their findings for $\mathrm{C} 2$ included a mean pars rostrocaudal angle of $36.59^{\circ}$ in males and $38.92^{\circ}$ in females and a mean pars axial angle of $39.76^{\circ}$ in males and $38.75^{\circ}$ in females. Linear measures included a mean pars axis length of $25.4 \mathrm{~mm}$ in males and $25.8 \mathrm{~mm}$ in females, a mean pedicle width of $6.9 \mathrm{~mm}$ in males and $6.5 \mathrm{~mm}$ in females, and a mean pedicle height of $11.3 \mathrm{~mm}$ in males

TABLE 4. Unadjusted analysis: effect of DS on the outcome, unadjusted for height*

\begin{tabular}{|c|c|c|c|c|}
\hline \multirow[b]{2}{*}{ Outcome } & \multicolumn{4}{|c|}{ Unadjusted Difference in Mean Outcomes } \\
\hline & Difference & SE & ES† & p Valuef \\
\hline Lamina angle, $^{\circ}$ & -1.16 & 1.02 & -0.33 & 0.953 \\
\hline Lamina height, $\mathrm{mm}$ & -2.6 & 0.6 & -1.39 & 0.001 \\
\hline Lamina length, $\mathrm{mm}$ & -1.4 & 0.6 & -0.77 & 0.136 \\
\hline Lamina width, mm & -1.4 & 0.3 & -1.27 & 0.001 \\
\hline Pedicle height, mm & -2.1 & 0.4 & -1.52 & $<0.001$ \\
\hline Pedicle width, mm & -1.4 & 0.5 & -0.84 & 0.051 \\
\hline Pars axial angle, ${ }^{\circ}$ & -5.55 & 1.41 & -1.15 & 0.003 \\
\hline Pars axis length, $\mathrm{mm}$ & -2.5 & 0.7 & -1.08 & 0.013 \\
\hline Pars rostrocaudal angle, ${ }^{\circ}$ & 5.32 & 1.51 & 1.07 & 0.012 \\
\hline $\begin{array}{l}\text { Transverse foramen pos- } \\
\text { terior distance, } \mathrm{mm}\end{array}$ & -2.7 & 0.4 & -2.17 & $<0.001$ \\
\hline \multicolumn{5}{|l|}{$\begin{array}{l}\text { Effect on lamina length by } \\
\text { side, mm§ }\end{array}$} \\
\hline Rt side & -1.0 & 0.6 & -0.50 & 0.104 \\
\hline Lt side & -1.9 & 0.6 & -1.06 & 0.003 \\
\hline \multicolumn{5}{|c|}{$\begin{array}{l}\text { Boldface type indicates statistical significance. } \\
\text { *Estimates come from mixed-effects models, with the average of the } 2 \text { raters' } \\
\text { measurements as outcome, DS indicator and side as fixed effects, and patient } \\
\text { as a random effect. } \\
\dagger \text { ES was calculated as the raw difference in means divided the pooled stand- } \\
\text { ard deviation of the outcome in DS and non-DS patients (Hedges' g). ES is } \\
\text { expressed in standard deviation units. } \\
\ddagger \text { p values were corrected for multiple comparisons using the Sidak method. } \\
\S \text { For each outcome, a model that included a side by DS interaction was first } \\
\text { fitted to check if the DS effect varied by side. The interaction term was not } \\
\text { statistically significant for } 9 \text { of the } 10 \text { outcomes, so it was dropped from the cor- } \\
\text { responding models, and a common effect of DS was estimated. The interaction } \\
\text { term was statistically significant for lamina length ( } p=0.047) \text {, so it was retained } \\
\text { in the model and the DS effect on lamina length was estimated separately for } \\
\text { each side (see last } 2 \text { rows above). For reference, the (overall) effect of DS on } \\
\text { lamina length ignoring the interaction term is also reported (see third row). }\end{array}$} \\
\hline
\end{tabular}


TABLE 5. Adjusted analysis: effect of DS on the outcome, adjusted for patient height*

\begin{tabular}{|c|c|c|c|c|}
\hline \multirow[b]{2}{*}{ Outcome } & \multicolumn{4}{|c|}{ Adjusted Difference in Mean Outcomes } \\
\hline & Difference & SE & Effect Size† & p Valuef \\
\hline Lamina angle, ${ }^{\circ}$ & -0.43 & 1.40 & -0.12 & $>0.99$ \\
\hline Lamina height, $\mathrm{mm}$ & -1.6 & 0.8 & -0.86 & 0.331 \\
\hline Lamina length, mm & -0.8 & 0.8 & -0.44 & 0.964 \\
\hline Lamina width, mm & -1.4 & 0.4 & -1.25 & 0.038 \\
\hline Pedicle height, mm & -1.3 & 0.5 & -0.93 & 0.072 \\
\hline Pedicle width, mm & -0.5 & 0.6 & -0.28 & 0.997 \\
\hline Pars axial angle, ${ }^{\circ}$ & -5.75 & 1.94 & -1.19 & 0.053 \\
\hline Pars axis length, $\mathrm{mm}$ & -1.5 & 1.0 & -0.64 & 0.766 \\
\hline Pars rostrocaudal angle, ${ }^{\circ}$ & 7.77 & 2.01 & 1.57 & 0.004 \\
\hline $\begin{array}{l}\text { Transverse foramen poste- } \\
\text { rior distance, } \mathrm{mm}\end{array}$ & -2.0 & 0.5 & -1.61 & 0.001 \\
\hline \multicolumn{5}{|l|}{$\begin{array}{l}\text { Effect on lamina length by } \\
\text { side, mm§ }\end{array}$} \\
\hline Rt side & -0.4 & 0.8 & -0.20 & 0.622 \\
\hline Lt side & -1.3 & 0.8 & -0.72 & 0.116 \\
\hline \multicolumn{5}{|c|}{$\begin{array}{l}\text { Boldface type indicates statistical significance. } \\
\text { *Estimates come from mixed-effects models, with the average of the } 2 \text { raters' } \\
\text { measurements as outcome; DS indicator, side; and height as fixed effects; and } \\
\text { patient as a random effect. } \\
\dagger \text { ES was calculated as the raw difference in means divided the pooled stand- } \\
\text { ard deviation of the outcome in DS and non-DS patients (Hedges’ g). ES is } \\
\text { expressed in standard deviation units. } \\
\ddagger p \text { values were corrected for multiple comparisons using the Sidak method. } \\
\S \text { For each outcome, a model that included a side by DS interaction was } \\
\text { first fitted to check if the DS effect varied by side. The interaction term was } \\
\text { not statistically significant for } 9 \text { of the } 10 \text { outcomes, so it was dropped from } \\
\text { the corresponding models, and a common effect of DS was estimated. The } \\
\text { interaction term was statistically significant for lamina length ( } p=0.047 \text { ), so it } \\
\text { was retained in the model and the DS effect on lamina length was estimated } \\
\text { separately for each side (see last } 2 \text { rows above). For reference, the (overall) } \\
\text { effect of DS on lamina length ignoring the interaction term is also reported (see } \\
\text { third row). }\end{array}$} \\
\hline
\end{tabular}

and $9.8 \mathrm{~mm}$ in females. These findings are similar to those in the present study, in which mean values for control patients included a pars rostrocaudal angle of $45.54^{\circ}$, pars axial angle of $35.72^{\circ}$, pars axis length of $30.0 \mathrm{~mm}$, pedicle width of $7.7 \mathrm{~mm}$, and pedicle height of $10.0 \mathrm{~mm}$. Similar to the present study, Karaikovic et al. ${ }^{9}$ demonstrated the effect of patient height on pedicle morphology.

When accounting for patient height, the pars rostrocaudal angle was generally larger in DS patients. With respect to $\mathrm{C} 2$ pedicle screw placement, a trajectory with a more rostral and less medial angulation than is typical may be necessary to achieve safe screw placement. The more posteriorly positioned boundary of the transverse foramen in DS patients, as illustrated by the negative transverse foramen posterior distance, may be a reflection of a narrower or more irregular pedicle. This may preclude safe $\mathrm{C} 2$ pedicle screw placement altogether in some patients with DS. Finally, the lamina width was smaller, which could impact placement of translaminar screws. This emphasizes the importance of careful preoperative imaging review to determine a safe trajectory for $\mathrm{C} 2$ screw placement or selection of an alternative site of fixation in patients with DS.
The present study demonstrated numerous anatomical differences between patients with and without DS when height was not taken into consideration. The effect of DS on all but 3 of the 10 anatomical measurements was statistically significant. It is vital to consider these results prior to accounting for height, since patients with DS are well known to have slower growth and shorter stature than their peers. ${ }^{3,4,18,28}$ Reduced lamina widths and heights could impact C2 laminar screw placement in some patients. Similarly, the smaller pars axis length and pedicle height in patients with DS may impact screw size selection, bony purchase, and construct stability.

DS is associated with a number of musculoskeletal disorders, particularly in the cervical spine. ${ }^{6}$ Atlantoaxial and atlantooccipital instability are particularly important concerns in this patient population due to the potential for acute or progressive myelopathy, respiratory failure, and quadriplegia. ${ }^{10}$ The prevalence of atlantoaxial and atlantooccipital instability has been estimated at $10 \%$ to $40 \%$. $^{1,2,6,7,16,19}$ Surgery to stabilize the upper cervical spine in patients with DS is fraught with risk. Several small series have shown rates of pseudarthrosis and loss of reduction ranging from $25 \%$ to $67 \% .{ }^{5,13,20,22,24}$ Similarly, rates of postoperative neurological deficit (8\% to 53\%) and reoperation (17\% to $42 \%$ ) are uncomfortably high., $513,20,24$ The origin of these high complication rates is likely multifactorial. However, developing an understanding of anatomical differences in the upper cervical spine of DS patients and a routine for careful preoperative structure-specific imaging analysis may help surgeons perform upper cervical arthrodesis more safely.

The present study is limited by its retrospective nature, its small sample size, poor interrater reliability for a minority of measurements, and the fact that only one of the DS patients presented with evidence of craniocervical instability. Future study in patients with overtly symptomatic instability is warranted, as there may be anatomical variations among a subgroup of patients with DS that could predispose them to upper cervical and craniocervical junction instability. In addition, further study of the safety of various C2 screw trajectories in patients with DS is warranted. While the present study provides a more concrete understanding of the surgically important anatomical differences in the C2 vertebra of patients with DS, and the role that patient height plays in many of these variables, it remains important to consider each patient individually. Careful preoperative planning with meticulous consideration of anatomical differences, both within the cervical spine and patient stature, is paramount for complication avoidance in DS patients with craniocervical instability.

\section{Conclusions}

Patients with DS had significantly smaller lamina width and transverse foramen posterior distance and significantly larger pars rostrocaudal angle than their age- and sexmatched peers after controlling for height. These measurements represent important considerations for placement of instrumentation, including pedicle, pars, and laminar screws, in DS patients. When placing instrumentation in the upper cervical spine in DS patients, surgeons should 
take these anatomical differences into account through careful study of preoperative fine-cut CT scans in order to optimize the potential for strong fixation and complication avoidance.

\section{References}

1. Ali FE, Al-Bustan MA, Al-Busairi WA, Al-Mulla FA, Esbaita EY: Cervical spine abnormalities associated with Down syndrome. Int Orthop 30:284-289, 2006

2. Alvarez N, Rubin L: Atlantoaxial instability in adults with Down syndrome: a clinical and radiological survey. Appl Res Ment Retard 7:67-78, 1986

3. Bull MJ: Health supervision for children with Down syndrome. Pediatrics 128:393-406, 2011

4. Cronk C, Crocker AC, Pueschel SM, Shea AM, Zackai E, Pickens G, et al: Growth charts for children with Down syndrome: 1 month to 18 years of age. Pediatrics 81:102-110, 1988

5. Doyle JS, Lauerman WC, Wood KB, Krause DR: Complications and long-term outcome of upper cervical spine arthrodesis in patients with Down syndrome. Spine (Phila Pa 1976) 21:1223-1231, 1996

6. Dumitrescu AV, Moga DC, Longmuir SQ, Olson RJ, Drack AV: Prevalence and characteristics of abnormal head posture in children with Down syndrome: a 20-year retrospective, descriptive review. Ophthalmology 118:1859-1864, 2011

7. El-Khouri M, Mourão MA, Tobo A, Battistella LR, Herrero CFP, Riberto M: Prevalence of atlanto-occipital and atlantoaxial instability in adults with Down syndrome. World Neurosurg 82:215-218, 2014

8. Fleiss JL: The Design and Analysis of Clinical Experiments. New York: Wiley, 1986

9. Karaikovic EE, Daubs MD, Madsen RW, Gaines RW Jr: Morphologic characteristics of human cervical pedicles. Spine (Phila Pa 1976) 22:493-500, 1997

10. McKay SD, Al-Omari A, Tomlinson LA, Dormans JP: Review of cervical spine anomalies in genetic syndromes. Spine (Phila Pa 1976) 37:E269-E277, 2012

11. Martich V, Ben-Ami T, Yousefzadeh DK, Roizen NJ: Hypoplastic posterior arch of C-1 in children with Down syndrome: a double jeopardy. Radiology 183:125-128, 1992

12. Miller JD, Capusten BM, Lampard R: Changes at the base of skull and cervical spine in Down syndrome. Can Assoc Radiol J 37:85-89, 1986

13. Nader-Sepahi A, Casey ATH, Hayward R, Crockard HA, Thompson D: Symptomatic atlantoaxial instability in Down syndrome. J Neurosurg 103 (3 Suppl):231-237, 2005

14. Nakamura N, Inaba Y, Aota Y, Oba M, Machida J, Aida N, et al: New radiological parameters for the assessment of atlantoaxial instability in children with Down syndrome: the normal values and the risk of spinal cord injury. Bone Joint J 98-B:1704-1710, 2016

15. Nakamura N, Inaba Y, Oba M, Aota Y, Morikawa Y, Ata Y, et al: Novel 2 radiographical measurements for atlantoaxial instability in children with Down syndrome. Spine (Phila Pa 1976) 39:E1566-E1574, 2014

16. Pizzutillo PD, Herman MJ: Cervical spine issues in Down syndrome. J Pediatr Orthop 25:253-259, 2005

17. Pueschel SM, Scola FH, Tupper TB, Pezzullo JC: Skeletal anomalies of the upper cervical spine in children with Down syndrome. J Pediatr Orthop 10:607-611, 1990

18. Rasmussen SA, Whitehead N, Collier SA, Frías JL: Setting a public health research agenda for Down syndrome: summary of a meeting sponsored by the Centers for Disease Control and Prevention and the National Down Syndrome Society. Am J Med Genet A 146A:2998-3010, 2008

19. Roy M, Baxter M, Roy A: Atlantoaxial instability in Down syndrome-guidelines for screening and detection. J R Soc Med 83:433-435, 1990

20. Segal LS, Drummond DS, Zanotti RM, Ecker ML, Mubarak SJ: Complications of posterior arthrodesis of the cervical spine in patients who have Down syndrome. J Bone Joint Surg Am 73:1547-1554, 1991

21. Sherman SL, Allen EG, Bean LH, Freeman SB: Epidemiology of Down syndrome. Ment Retard Dev Disabil Res Rev 13:221-227, 2007

22. Shikata J, Yamamuro T, Mikawa Y, Iida H, Kobori M: Atlanto-axial subluxation in Down's syndrome. Int Orthop 13:187-192, 1989

23. Siemionow K, Chou D: To the occiput or not? C1-C2 ligamentous laxity in children with Down syndrome. Evid Based Spine Care J 5:112-118, 2014

24. Siemionow K, Hansdorfer M, Janusz P, Mardjetko S: Complications in adult patients with Down syndrome undergoing cervical spine surgery using current instrumentation techniques and rhBMP-2: A long-term follow-up. J Neurol Surg A Cent Eur Neurosurg 78:113-123, 2017

25. Wakao N, Takeuchi M, Nishimura M, Riew KD, Kamiya M, Hirasawa A, et al: Vertebral artery variations and osseous anomaly at the C1-2 level diagnosed by 3D CT angiography in normal subjects. Neuroradiology 56:843-849, 2014

26. Xu R, Nadaud MC, Ebraheim NA, Yeasting RA: Morphology of the second cervical vertebra and the posterior projection of the C2 pedicle axis. Spine (Phila Pa 1976) 20:259-263, 1995

27. Yamazaki M, Okawa A, Hashimoto M, Aiba A, Someya Y, Koda M: Abnormal course of the vertebral artery at the craniovertebral junction in patients with Down syndrome visualized by three-dimensional CT angiography. Neuroradiology 50:485-490, 2008

28. Zemel BS, Pipan M, Stallings VA, Hall W, Schadt K, Freedman DS, et al: Growth charts for children with Down syndrome in the United States. Pediatrics 136:e1204-e1211, 2015

\section{Disclosures}

Dr. Nockels: consultant for Medtronic. Dr. Jones: grant from Medtronic through Loyola University Medical Center for an unrelated research project, stock ownership in InVivo Therapeutics, and honorarium for the Chicago Review Course.

\section{Author Contributions}

Conception and design: Jones, Rosenblum, Nockels. Acquisition of data: Hofler, Heiferman, Rosenblum. Analysis and interpretation of data: Jones, Hofler, Heiferman, Molefe, Johans, Nockels. Drafting the article: Jones, Hofler, Heiferman, Molefe, LeDuc, Johans, Nockels. Critically revising the article: all authors. Reviewed submitted version of manuscript: all authors. Approved the final version of the manuscript on behalf of all authors: Jones. Statistical analysis: Molefe. Administrative/technical/material support: Jones. Study supervision: Jones.

\section{Supplemental Information \\ Previous Presentations}

An abstract derived from preliminary data from this project was presented as a digital poster at the 34th Annual Meeting of the Cervical Spine Research Society European Section, Lisbon, Portugal, on May 9-11, 2018.

\section{Correspondence}

G. Alexander Jones: Loyola University Medical Center, Maywood, IL. alexander.jones@lumc.edu. 